\title{
Clinical Significance of Elevated Serum Caspase-1 Levels in Patients With Ankylosing Spondylitis
}

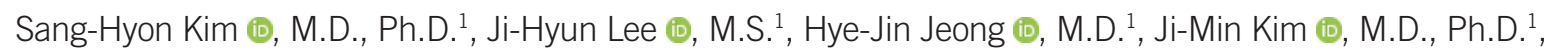

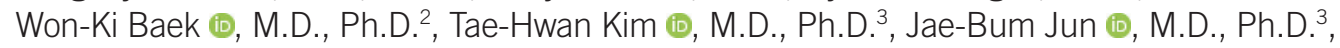
and Chang-Nam Son (iD, M.D., Ph.D. ${ }^{1,4}$

${ }^{1}$ Division of Rheumatology, Department of Internal Medicine, Keimyung University School of Medicine, Daegu, Korea; ${ }^{2}$ Department of Microbiology, Keimyung University School of Medicine, Daegu, Korea; ${ }^{3}$ Department of Rheumatology, Hanyang University Hospital for Rheumatic Diseases, Seoul, Korea; ${ }^{4}$ Institute for Cancer Research, Keimyung University, Daegu, Korea

Dear Editor,

Ankylosing spondylitis (AS) is a chronic autoimmune disease that affects the axial skeleton and peripheral joints [1]. Although several etiologies for AS have been proposed, no clear cause has been identified to date [2]. Activated caspase-1 within the nucleotide-binding oligomerization domain-like receptor pyrin domain-containing-3 (NLRP3) inflammasome converts pro-interleukin (IL)-1 $\beta$ and pro-IL-18 into their biologically active forms, $\mathrm{IL}-1 \beta$ and IL-18, respectively [3]. Given that AS is an inflammatory disease, it is hypothesized that inflammasomes activated during the immune response, such as the NLRP3 inflammasome, contribute to disease development and progression [4, 5]. Previously, we demonstrated that caspase-1 levels in the synovial fluid are higher in patients with spondyloarthritis than in patients with other types of arthritides [6]. In this study, we investigated whether serum caspase-1 level differentiates AS from other rheumatic diseases and examined the relationship between serum caspase- 1 levels and AS disease activity.

Between June 2017 and August 2018, 126 study participants (20 AS, 23 gout, and 62 rheumatoid arthritis [RA] patients; 21 healthy controls) from Keimyung University Dongsan Hospital in Daegu were enrolled. The study was approved by the institutional review board (IRB; 2017-06-021) and conducted in accordance with the Declaration of Helsinki. Written informed consent was obtained from all participants. Blood samples were collected from each patient prior to initiating medical treatment. Patients met the 1984 New York criteria for AS [7], the 2010 RA classification criteria for RA [8], or had acute gout [9]. The control group consisted of healthy healthcare workers. We collected age, sex, disease duration, and blood chemistry data from all participants.

A second cohort of 22 AS patients was recruited from an outpatient rheumatology clinic at Hanyang University Hospital for Rheumatic Diseases, Seoul, Korea, and their serum caspase-1 levels were compared with indicators of AS disease activity. The study was approved by the IRB of Hanyang University Hospital (2008-09-001). Written informed consent was obtained from all patients. Blood samples were collected from AS patients for routine examination between September 2017 and March 2019.

We analyzed the relationship between serum caspase-1 level and serum erythrocyte sedimentation rate (ESR), C-reactive protein (CRP), the Bath Ankylosing Spondylitis Disease Activity Index and Ankylosing Spondylitis Disease Activity Score [1]. Caspase-1, IL-1 $\beta$, IL-18, and NLRP3 levels were measured using
Received: January 20, 2021

Revision received: March 6, 2021

Accepted: September 13, 2021

Corresponding author: Chang-Nam Son, M.D., Ph.D.

Division of Rheumatology, Department of Internal Medicine, Keimyung University School of Medicine, 1035 Dalgubeol-daero, Dalseo-gu, Daegu 42601, Korea

Tel: +82-53-258-7733, Fax: +82-53-258-4976; E-mail: cnson@kmu.ac.kr

\section{(c) (1) $(9$}

(C) Korean Society for Laboratory Medicine

This is an Open Access article distributed under the terms of the Creative Commons Attribution Non-Commercial License (https://creativecommons.org/licenses/by-nc/4.0) which permits unrestricted non-commercial use, distribution, and reproduction in any medium, provided the original work is properly cited. 
Table 1. Clinical and laboratory features of patients with ankylosing spondylitis, gout, and rheumatoid arthritis compared with healthy controls

\begin{tabular}{|c|c|c|c|c|c|}
\hline Feature* & $\begin{array}{l}\text { Ankylosing spondylitis } \\
\qquad(\mathrm{N}=20)\end{array}$ & $\begin{array}{c}\text { Gout } \\
(\mathrm{N}=23)\end{array}$ & $\begin{array}{l}\text { Rheumatoid arthritis } \\
\qquad(\mathrm{N}=62)\end{array}$ & $\begin{array}{l}\text { Healthy controls } \\
\qquad(\mathrm{N}=21)\end{array}$ & $P^{\dagger}$ \\
\hline Age (yr) & $35.5(21.0)$ & $56.0(25.0)$ & $61.5(9.0)$ & $41.0(23.0)$ & $<0.001 *$ \\
\hline $\operatorname{Sex}(M / F)$ & $18 / 2$ & $20 / 3$ & $24 / 38$ & $1 / 20$ & \\
\hline $\mathrm{ESR}(\mathrm{mm} / \mathrm{hr})$ & $20.0(41.5)$ & $43.5(30.0)(\mathrm{N}=10)$ & $40.5(56.0)$ & NA & 0.316 \\
\hline $\mathrm{CRP}(\mathrm{mg} / \mathrm{dL})$ & $0.2(1.6)$ & $2.41(8.14)(\mathrm{N}=10)$ & $0.32(1.75)$ & NA & 0.020 \\
\hline WBC $\left(\times 10^{9} / L\right)$ & $7.1(2.6)$ & $8.2(6.0)(\mathrm{N}=11)$ & $7.6(3.8)$ & NA & 0.460 \\
\hline Caspase-1 (pg/mL) & $201.1(109.8)$ & $137.3(91.7)$ & $144.6(150.8)$ & $71.5(72.9)$ & $<0.001$ \\
\hline IL-1 (pg/mL) & $2.39(3.95)$ & $4.1(1.9)$ & $2.1(3.5)$ & $6.1(2.5)$ & $<0.001$ \\
\hline IL-18 (pg/mL) & $1,585(127)$ & $1,520(176)$ & $1,572(118)$ & 1,695 (199) & 0.014 \\
\hline NLRP3 (pg/mL) & $0.2(0.3)$ & $0.5(1.0)$ & $0.6(1.3)$ & $0.0(0.1)$ & $<0.001$ \\
\hline Caspase-1 >125 pg/mL ${ }^{\ddagger}$ & $16(80.0 \%)$ & $15(65.2 \%)$ & 39 (62.9\%) & $3(14.3 \%)$ & $<0.001$ \\
\hline
\end{tabular}

${ }^{*}$ Continuous variables are shown as median (interquartile range); ${ }^{\dagger} P$ values were determined using the Kruskal-Wallis test; bold numbers indicate statistical significance; ${ }^{\ddagger}$ The frequency of high levels ( $\geq 125 \mathrm{pg} / \mathrm{mL}$ ) of serum caspase- 1 was significantly higher in ankylosing spondylitis than in the other groups as revealed by Fisher's exact test.

Abbreviations: ESR, erythrocyte sedimentation rate; CRP, C-reactive protein; WBC, white blood cells; IL, interleukin; NLRP3, nucleotide-binding oligomerization domain-like receptor pyrin domain-containing-3; NA, not available.

ELISA kits (Quantikine, R\&D Systems, Minneapolis, MN, USA; Aviva Systems Biology, San Diego, CA, USA). Statistical analyses were performed using SPSS version 25.0 (IBM, Armonk, NY, USA). Results are presented as median (interquartile range) or frequency (\%). For continuous variables, the Mann-Whitney $U$ test was used to compare the high CRP group with the normal CRP group and the Kruskal-Wallis test for between-group comparisons of AS, gout, RA, and healthy controls. For categorical variables, Fisher's exact test was used to compare the frequency of high levels ( $>125 \mathrm{pg} / \mathrm{mL}$ ) of caspase-1 between groups. $P<$ 0.05 was considered statistically significant.

The summary statistics of the patients are presented in Table 1. The mean serum caspase-1 level was significantly higher in AS patients than in other groups $(P<0.001)$. The frequency of caspase- 1 level $\geq 125 \mathrm{pg} / \mathrm{mL}$ was also higher in the AS group than in the gout, RA, and healthy control groups. When we compared serum caspase-1 level according to high and normal CRP levels in the independent sample set, serum caspase- 1 level was significantly higher in the high CRP groups than in the normal CRP group ( $P=0.041$, Table 2 ).

Significantly higher caspase-1 levels were observed in spondyloarthritis than in other arthritic diseases, including gout, inflammatory arthritis, and osteoarthritis [6]. Concordantly, we found higher serum caspase-1 level in AS patients than in patients with other diseases and healthy controls, and patients with high CRP level had elevated serum caspase-1 levels. Caspase-1 activation is the hallmark of inflammasome activation [4],
Table 2. Serologic and clinical features of patients with ankylosing spondylitis classified by CRP level in the independent sample set

\begin{tabular}{lccr}
\hline Feature* & $\begin{array}{c}\text { High CRP } \\
(\geq 0.8 \mathrm{mg} / \mathrm{L}) \\
(\mathrm{N}=12)\end{array}$ & $\begin{array}{c}\text { Normal CRP } \\
(<0.8 \mathrm{mg} / \mathrm{L}) \\
(\mathrm{N}=10)\end{array}$ & $P^{\dagger}$ \\
\hline Age (yr) & $29.5(4.0)$ & $30.0(9.0)$ & 0.205 \\
Sex (M/F) & $11 / 1$ & $10 / 0$ & \\
Disease duration (month) & $21.0(85.5)$ & $33.5(86.0)$ & 0.865 \\
ESR (mm/hr) & $42.5(34.5)$ & $4.5(7.0)$ & $<\mathbf{0 . 0 0 1}$ \\
Caspase-1 (pg/mL) & $86.7(130.1)$ & $32.1(56.2)$ & $\mathbf{0 . 0 4 1}$ \\
BASDAl & $5.1(2.1)$ & $1.9(3.4)$ & $\mathbf{0 . 0 2 1}$ \\
ASDAS-CRP & $3.8(1.0)$ & $1.8(1.8)$ & $\mathbf{0 . 0 0 2}$ \\
Peripheral arthritis & $4(33 \%)$ & $5(50 \%)$ & \\
\hline
\end{tabular}

${ }^{*}$ Continuous variables are shown as median (interquartile range); ${ }^{\dagger} P$ values were determined using the Kruskal-Wallis test, bold numbers indicate statistical significance.

Abbreviations: CRP, C-reactive protein; ESR, erythrocyte sedimentation rate; BASDAI, Bath Ankylosing Spondylitis Disease Activity Index; ASDAS, Ankylosing Spondylitis Disease Activity Score.

which is essential in inflammatory response induction in macrophages. A chronic inflammatory response is a major risk factor for autoimmune disease development. In AS patients, macrophages are abundantly present in not only synovial tissues but also sacroiliac joint and colonic mucosal tissues [6].

This study had some limitations. Because of the difficulty in obtaining a clinical sample from patients with high disease activity, the sample size was relatively small. Examining more di- 
rect evidence of the role of caspase- 1 in AS is required. Further validation using larger sample sizes, alternative sample types (urine and bone), and animal models can help identify biomarkers for AS.

This study was the first to assess the association between serum caspase-1 level and AS. Serum caspase-1 levels were the highest in AS patients when compared with those in patients with other inflammatory arthropathies and healthy controls. Further, we observed high serum caspase-1 levels in AS patients that had high CRP levels. There is no clinically available biomarker for the early diagnosis or monitoring of AS. Our results suggest that serum caspase- 1 is a helpful biomarker for AS and should be further investigated.

\section{ACKNOWLEDGEMENTS}

Biospecimens were provided by Keimyung University Dongsan Hospital Korea Regional Biobank, a member of the National Biobank of Korea, which is supported by the Ministry of Health and Welfare.

\section{AUTHOR CONTRIBUTIONS}

Kim SH, Kim TH, Jun JB, and Son CN contributed to the study conception. Lee JH, Jeong HJ, Kim JM, Kim TH, and Son CN contributed to data curation. Kim SH, Jeong HJ, Kim TH, and Son $\mathrm{CN}$ performed the formal analysis. Son $\mathrm{CN}$ obtained funding for the project. Baek WK, Kim TH, Jun JB, and Son CN contributed to the methodology of the study. Kim SH, Jeong HJ, Kim JM, Baek WK, Kim TH, and Son CN administered the project. Kim SH, Kim TH, and Son CN wrote the draft of the manuscript. All authors reviewed and edited the manuscript.

\section{CONFLICTS OF INTEREST}

None declared.

\section{RESEARCH FUNDING}

This work was supported by a research promoting grant from the Institute for Cancer Research Keimyung University Dongsan Medical Center in 2017.

\section{ORCID}

Sang-Hyon Kim

Ji-Hyun Lee

Hye-Jin Jeong

Ji-Min Kim

Won-Ki Baek

Tae-Hwan Kim

Jae-Bum Jun

Chang-Nam Son https://orcid.org/0000-0002-8030-7939

https://orcid.org/0000-0002-5794-8367

https://orcid.org/0000-0002-5989-7612

https://orcid.org/0000-0002-3894-3413

https://orcid.org/0000-0001-9123-4096

https://orcid.org/0000-0002-3542-2276

https://orcid.org/0000-0002-0208-0505

https://orcid.org/0000-0002-1722-2190

\section{REFERENCES}

1. Kiltz $U$ and Braun J. Assessments of functioning in patients with axial spondyloarthritis. J Rheum Dis 2020;27:22-9.

2. Ranganathan V, Gracey E, Brown MA, Inman RD, Haroon N. Pathogenesis of ankylosing spondylitis - recent advances and future directions. Nat Rev Rheumatol 2017;13:359-67.

3. Spel $L$ and Martinon F. Inflammasomes contributing to inflammation in arthritis. Immunol Rev 2020;294:48-62.

4. Yi YS. Role of inflammasomes in inflammatory autoimmune rheumatic diseases. Korean J Physiol Pharmacol 2018;22:1-15.

5. Kim SK, Cho YJ, Choe JY. NLRP3 inflammasomes and NLRP3 inflammasome-derived proinflammatory cytokines in peripheral blood mononuclear cells of patients with ankylosing spondylitis. Clin Chim Acta 2018; 486:269-74.

6. Son CN, Bang SY, Kim JH, Choi CB, Kim TH, Jun JB. Caspase-1 level in synovial fluid is high in patients with spondyloarthropathy but not in patients with gout. J Korean Med Sci 2013;28:1289-92.

7. van der Linden S, Valkenburg HA, Cats A. Evaluation of diagnostic criteria for ankylosing spondylitis. A proposal for modification of the New York criteria. Arthritis Rheum 1984;27:361-8.

8. Aletaha D, Neogi T, Silman AJ, Funovits J, Felson DT, Bingham CO 3rd, et al. 2010 Rheumatoid arthritis classification criteria: an American College of Rheumatology/European League Against Rheumatism collaborative initiative. Arthritis Rheum 2010;62:2569-81.

9. Wallace SL, Robinson H, Masi AT, Decker JL, McCraty DJ, Yu TF. Preliminary criteria for the classification of the acute arthritis of primary gout. Arthritis Rheum 1977;20:895-900. 